\title{
Editorial
}

\section{Public Health Nutrition for this decade}

You will notice from the contents list beginning with this issue that we have made some adjustments to our journal. These follow from a discussion at a meeting of our editorial board together with representatives of the Nutrition Society and Cambridge University Press, held on the occasion of the International Conference on Nutrition in Bangkok last October.

The field of public health nutrition, as learned, taught and practised, is relatively new and rapidly evolving. Its issues are broad, complex and multidisciplinary. In a dynamic environment, our journal needs to ensure that it has optimal relevance to our topic and for you, our readers. Accordingly, we have now adjusted the aims and scope of the journal, and introduced related categories for papers, to give the journal an internal structure and to guide editors, reviewers, contributors and readers.

\begin{abstract}
Aims
The scope of Public Health Nutrition includes food systems and supplies, patterns of diet, foods and drinks, nutrients, body composition, physical activity and associated factors, and their effects on disease, health and well-being, and on the whole living and physical worlds.

Our revised aims highlight a number of key objectives of this journal, as shown in bold type below:

Public Health Nutrition provides an international

forum for the publication and dissemination of research and scholarship in the form of peerreviewed original papers and reviews, and for discussion in the form of editorials, commentary and correspondence with a specific focus on nutrition-related public health.
\end{abstract}

This journal has always been international in terms of the origin of contributing authors and published papers. The emphasis on research and scholarship recognises the importance of different paradigms. External peer-review ensures and enhances the quality of research findings. We also aim to stimulate discussion and debate. And finally, we see public health nutrition as one vital part of the discipline of public health, and therefore inextricably linked to all the sciences that discipline encompasses: social, economic, political, environmental, as well as biological and behavioural.

\section{Standards}

We are now receiving more and more papers for consideration. This means that we have to raise the standards for acceptance of papers, while always taking into account contributors from less-resourced parts of the world. We are now asking our editors and reviewers to have sharper eyes for quality and relevance.

As a guide to contributors, we prefer papers that are innovative (do not report on research already undertaken elsewhere) and succinct (well under 5000 words including references). Authors may be asked to shorten papers, and annexes and illustrative supporting material may be published online only. Short communications are welcome. We prefer research, scholarship and discussions that take a population, health-promoting and preventive approach. Papers that do not have this emphasis will be directed to more appropriate journals.

\section{Scope}

As from now authors are asked to position their contributions within the scope and categories outlined in the table on the following page which, we believe, encompass public health nutrition in the broader sense according to definitions above, as studied and practised.

We hope that these guidelines will encourage papers that are increasingly relevant and trenchant. If potential contributors feel that their papers do not fit within this scope and these categories they should please say so. Currently we are particularly looking for papers reporting on high-quality interventions, and also papers on public policy and professional capacity building. Our discipline badly needs more work in these areas in order to build a stronger evidence base. We look forward to your contributions this year and during the years to come!
Agneta Yngve

Editor-in-Chief

Geoffrey Cannon

Roger Hughes

Barrie Margetts

Marilyn Tseng

Deputy Editors 
Public Health Nutrition: scope and categories of papers to take effect as from $\mathbf{2 0 1 0}$

\begin{tabular}{ll}
\hline Scope & Category of papers \\
\hline $\begin{array}{l}\text { Address nutritional status assessment, monitoring } \\
\text { and surveillance }\end{array}$ & $\begin{array}{c}\text { Monitoring and surveillance } \\
\text { Assessment and methodology }\end{array}$ \\
$\begin{array}{l}\text { Identify and analyse social, cultural, biological, environmental, economic } \\
\text { and political determinants of nutrition-related public health }\end{array}$ & $\begin{array}{c}\text { Biological and behavioural determinants } \\
\text { Social, economic, political and } \\
\text { environmental determinants }\end{array}$ \\
$\begin{array}{l}\text { Build intelligence about the development, implementation and evaluation of } \\
\text { public health nutrition interventions }\end{array}$ & Interventions \\
$\begin{array}{l}\text { Describe, discuss, debate } \\
\text { and influence food and nutrition policy }\end{array}$ & Public policies \\
$\begin{array}{l}\text { Focus on improving food and nutrition-related public health, particularly in } \\
\text { those populations that are most vulnerable and at risk }\end{array}$ & Special groups \\
$\begin{array}{l}\text { Discuss and build capacity } \\
\text { for effective public health nutrition action, including workforce } \\
\text { development and educational issues }\end{array}$ & Capacity building \\
$\begin{array}{l}\text { Develop and test new models, methods and approaches to public health } \\
\text { nutrition practice and research }\end{array}$ & Innovation \\
\hline
\end{tabular}

\section{Announcement}

\section{WHO launches the Nutrition Landscape Information System (NLIS)}

The NLIS is developed as a component of the Landscape Analysis on Countries' Readiness to Accelerate Action in Nutrition which was a project funded by the Bill and Melinda Gates Foundation (http://www.who.int/ nutrition/topics/landscape_analysis/en/index.html).

This web-based information system provides nutrition and nutrition-related health and development data in the form of both automated country profiles and userdefined downloadable data which pull together the data from the WHO Nutrition Databases dynamically.

The NLIS draws data for the country profiles from available databases. Sources include WHO, UNICEF, UN Statistics Division, UNDP, FAO, DHS, the World Bank, IFPRI and ILO. The data from these partner agencies are updated every 2 months. However, more recent data might be available from other sources, including incountry sources.

The NLIS is still work in progress and will continued to be in order to achieve continued enhancement and update. The first phase has been accomplished and it has met the first milestone as one of the interagency products of the Landscape Analysis project, through achieving:

- Improved access to comprehensive nutrition information across multiple sources from our partner agencies (Efficiency)

- Combined information using the UNICEF conceptual framework which will facilitate and contribute to more integrated approaches to scaling up effective nutrition interventions (Integration)

- Linked dynamically to WHO Global Nutrition Databases (Timeliness)

- Easy access to quality information compiled by the partner agencies, leading to more informed decisionmaking (Accessibility)

- Most indicators available for all countries (Comprehensiveness).

NLIS can be accessed directly at http://www.who.int/ nutrition/nlis or through the NHD website at http://www. who.int/nutrition (see the right hand top corner). 